\title{
CONTROL AND EXPERIMENTAL EVALUATION ON A QUARTER-CAR TEST RIG
}

\author{
Bahaa-Aldin R. Abdullah ${ }^{1} \quad$ Mohsin N. Hamzah $^{2} \quad$ Ammar S. Merza $^{3}$ \\ engbahaa311@ gmail.com, ${ }^{2}$ 20066@uotechnology.edu.iq, ${ }^{3}$ 20086@uotechnology.edu.iq \\ University of Technology/Mechanical Engineering Department
}

\begin{abstract}
In this paper a quarter-vehicle full-scale suspension test rig was designed and manufactured, the suspension is considered semi-active as the electrohydraulic (EH) damper used is fully controlled. This gives an indoor-based simulation tool which is important for vehicle testing;. This reduces the cost significantly with accurate results, especially when designing a new suspension system. The aim of the current work was to build a new quarter-vehicle test rig with expandable capabilities for diverse design objectives, also may be used for academic purposes. The control objective was achieved by using dynamic characteristics of the electrohydraulic $(\mathrm{EH})$ damper to suppress the oscillation of the sprung mass due to road irregularities. The test rig was constructed using a Genesis G80 (2016) suspension system. Finally, the simulation results demonstrated that the proposed controller used be able to efficiently regulate the chassis vertical oscillation under these irregularities. The experimental results for the quarter-car model showed good results between experimental and simulated results, where the proportion of conformity about $95 \%$.
\end{abstract}

KEYWORDS: Suspension system; quarter-vehicle, test rig

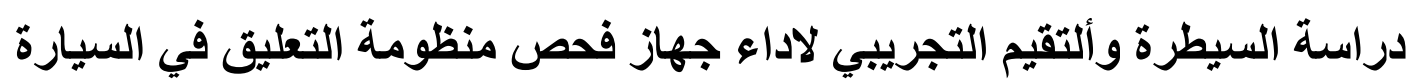

$$
\text { بهاء الدين رسول عبدالله محسن نوري حمزه عمار سليم مرزه }
$$

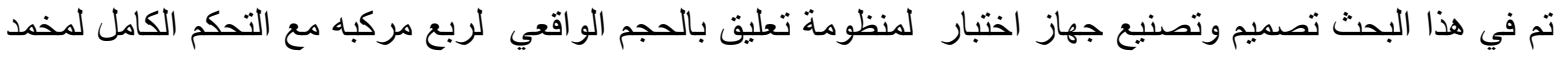

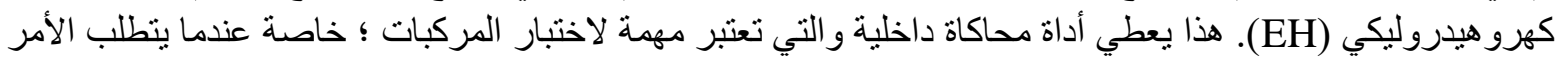

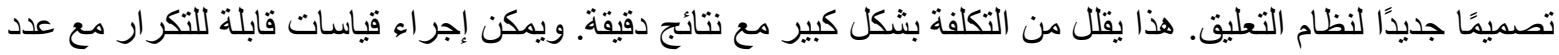

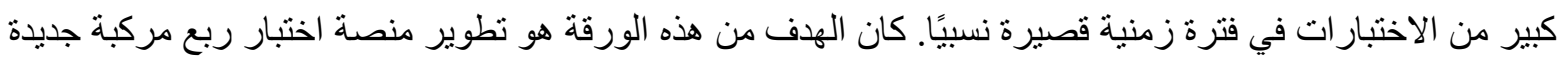

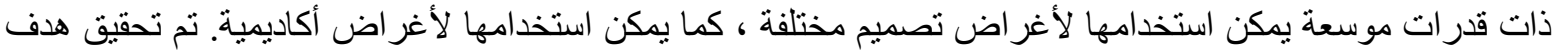

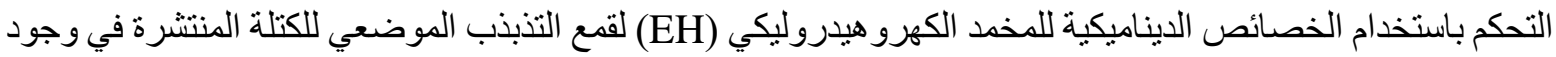

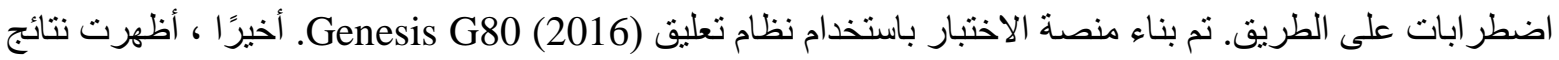

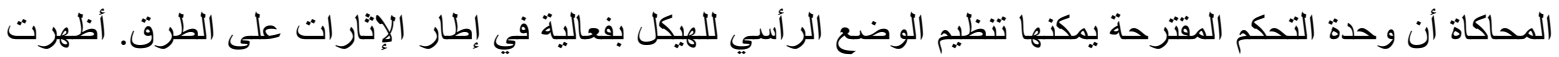

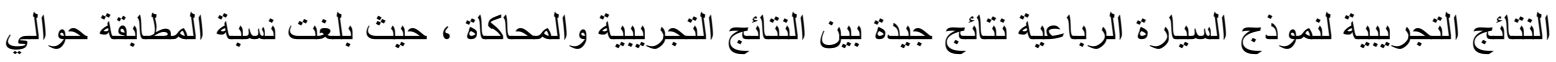




\section{INTRODUCTION}

Independent suspension system is a vital element of a vehicle to isolate it from the road irregularities.A distinctive car with a suspension system is needed for maintaining a progressive contact between road and the tires of vehicle. The damper is considered as the highly significant element of the suspension system. It decreases the results of an unanticipated bump on the road via reducing the roughness of shock. In majority of absorbers of shock, the energy of vibration is first changed to heat and then dispelled into the surrounding. In a viscous damper, the energy is converted to heat due to the presence of viscous fluid, therefore the fluid is becomes hot (Nagarajah, and Ektesabi 2018). Nevertheless, there are still many challenges that must be avoided for such techniques to realize their entire capability. The degradation of magnetorheological (MR) by the time, problems of sealing and sensitivity of temperature are few crucial topics of the MR dampers that require evolution. The main objective of the suspension system is to provide a smooth ride, as a result improving the ride comfort, consequently a larger suspension stroke and smaller damping in the wheel hop mode is produced (Aly 2012). In this paper, the damping characteristics of the suspension system is adjusted via the use of the electrohydraulic $(\mathrm{EH})$ damper, the damping ratio is continuously changing by means of modifying the size of orifices, this is done by the solenoid valves located inside or outside the main body of the damper. More attention were paid by many researchers on the use of semi-active suspension system. Contemporary advances in variable fluid viscosity damper encouraging the use in the semi-active suspension, especially, the use of electrorheological (ER) and magnetorheological (MR) fluids due to their wide viscosity range and high bandwidths (Savaresi et al.2010) and (Bangsing et al.2011). The skyhook control is considered as a good control strategy, which a fictitious damper is inserted between the sprung mass and the stationary sky, as a results suppressing the vibratory motion of the sprung mass, consequently computing the desired damping force and reductions of the resonant peak, this gives a good ride quality. On the other hand, in order to improve the handling performance of a vehicle as well, both resonant peaks of the unsprung mass and the sprung mass have to be reduced (Priyandoko et al.2009)( Swevers et al.2007), (Suh, and Yeo 2000)and (Eltantawie 2012). This paper aims to design a full scale quarter-car test rig platform to check the performance of the automotive semi-active suspension system. And to contribute to the investigation of semi-active suspension systems with skyhook controller.

\section{EXPERIMENTAL WORK}

\section{Quarter Car Test Rig}

A quarter-car test rig shown in figure(1) was designed and manufactured in order to study the performance of the semi-active suspension system under various road irregularities, This enable to test a full-scale platform rig to evaluate the performance of the automotive suspension system. The basic components of this rig are as follows: base plate, linear guides, adapter plate, the quarter car suspension with tire, and the pneumatic actuator. The dimension of the base plate was $110 \mathrm{~cm} \times 70 \mathrm{~cm}$ and $10 \mathrm{~mm}$ thickness; this gives a rigid frame for this rig. The base has a trolley guide slot that carries the bump, and moves in a linear motion using a pneumatic cylinder and moves in a specific stroke along the piston. The reaction fixture is the structure that constrains the motion of the sprung mass vertically through linear bearings. The fixture is a steel plate of dimensions $209 \times 20 \mathrm{~cm}$ wide. The sliding bearing rails are SKF with low friction. 


\section{Experimental characterization}

For the test rig shown in Figure(1), the input to the system is generated via the use of the pneumatic cylinder shown by using some kind of control driven by the use of Matlab, the kind of signal is a step input excitation signal. The acceleration for both sprung mass and unsprung mass are measured by the use of two G-sensors. All sensors data input during the control action are recorded instantaneously by DAQ system.

\section{Quarter Car Model}

Consider a two-DOF quarter car model shown in Figure (2), this model uses the linearity within the suspension spring and damper forces that have a vital influence on the responses of the suspension when excited by completely different road inputs (Malekshahi and Mirzaei 2012) . The main components are: sprung mass $\left(m_{s}\right)$, unsprung mass $\left(m_{u s}\right)$, spring stiffness $k_{s}$, tire stiffness of $\mathrm{k}_{\mathrm{t}}$, and a semi-active damper connected both masses. In this model, $\mathrm{z}_{1}$ and $\mathrm{z}_{2}$ are the vertical position of $m_{u s}$ and $m_{s}$, respectively. And, $z_{o}$ is the road input (or irregularities) (Spelta et al. 2010). The differential equations of motion are:

$m_{s} \ddot{z}_{2}+c\left(\dot{z}_{2}-\dot{z}_{1}\right)+k_{s}\left(z_{2}-z_{1}\right)+f_{d}=0$

$m_{u s} \ddot{z}_{1}-c\left(\dot{z}_{2}-\dot{z}_{1}\right)+z_{1}\left(k_{t}+k_{s}\right)-k_{t} z_{s}-k_{s} z_{2}-f_{d}=0$

$\mathrm{X}_{1}=\mathrm{Z}_{1}, \mathrm{X}_{2}=\mathrm{Z}_{2}, \mathrm{X}_{3}=\mathrm{Z}_{1}{ }^{\prime}, \mathrm{X}_{4}=\mathrm{Z}_{2}{ }^{\prime}$,

then the system state equation can be expressed as:

$\mathrm{X}^{\prime}=\mathrm{AX}+\mathrm{BU}$

$\mathrm{X}^{\prime}=\left[\mathrm{X}_{1}, \mathrm{X}_{2}, \mathrm{X}_{3}, \mathrm{X}_{4}\right] ; \quad \mathrm{U}=\left[\mathrm{Z}_{\mathrm{o}}, \mathrm{F}_{\mathrm{d}}\right]$

Of which

$\mathrm{X}^{\prime}{ }_{1}=0 \times \mathrm{X}_{1}+0 \times \mathrm{X}_{2}+\mathrm{X}_{3}+0 \times \mathrm{X}_{4}$

$\mathrm{X}_{2}{ }_{2}=0 \times \mathrm{X}_{1}+0 \times \mathrm{X}_{2}+0 \times \mathrm{X}_{3}+\mathrm{X}_{4}$

$\mathrm{X}_{3}=\frac{-k t+k s}{m u s} \times \mathrm{X}_{1}+\frac{k s}{m u s} \times \mathrm{X}_{2}-\frac{c}{m u s} \times \mathrm{X}_{3}+\frac{c}{m u s} \times \mathrm{X}_{4}$

$\mathrm{X}^{\prime}{ }_{4}=\frac{\mathrm{ks}}{\mathrm{ms}} \times \mathrm{X}_{1}-\frac{\mathrm{ks}}{\mathrm{ms}} \times \mathrm{X}_{2}+\frac{c}{\mathrm{~ms}} \times \mathrm{X}_{3}-\frac{c}{\mathrm{~ms}} \times \mathrm{X}_{4}$

State space equation can be written as form,

$\left[\begin{array}{l}x_{1}^{\prime} \\ x_{2}^{\prime} \\ x_{3}^{\prime} \\ x_{4}^{\prime}\end{array}\right]=\left[\begin{array}{cccc}0 & 0 & 1 & 0 \\ 0 & 0 & 0 & 1 \\ \frac{-k t+k s}{m u s} & \frac{k s}{m u s} & \frac{-c}{m u s} & \frac{c}{m u s} \\ \frac{k s}{m s} & \frac{-k s}{m s} & \frac{c}{m s} & \frac{-c}{m s}\end{array}\right]\left[\begin{array}{l}x_{1} \\ x_{2} \\ x_{3} \\ x_{4}\end{array}\right]+\left[\begin{array}{cc}0 & 0 \\ 0 & 0 \\ \frac{k t}{m u s} & \frac{1}{m u s} \\ 0 & \frac{-1}{m s}\end{array}\right] \mathrm{U}$

where,

$\mathrm{A}=\left[\begin{array}{cccc}0 & 0 & 1 & 0 \\ 0 & 0 & 0 & 1 \\ \frac{-k t+k s}{m u s} & \frac{k s}{m u s} & \frac{-c}{m u s} & \frac{c}{m u s} \\ \frac{k s}{m s} & \frac{-k s}{m s} & \frac{c}{m s} & \frac{-c}{m s}\end{array}\right], \quad \mathrm{B}=\left[\begin{array}{cc}0 & 0 \\ 0 & 0 \\ \frac{k t}{m u s} & \frac{1}{m u s} \\ 0 & \frac{-1}{m s}\end{array}\right]$ 
$\mathrm{Y}=\mathrm{CX}+\mathrm{DU}$

$\mathrm{C}=\left[\begin{array}{cccc}-k s & 0 & 0 & 0 \\ \frac{k s}{m s} & \frac{-k s}{m s} & \frac{c}{m s} & \frac{-c}{m s} \\ 1 & -1 & 0 & 0\end{array}\right], \quad \mathrm{D}=\left[\begin{array}{cc}k t & 0 \\ 0 & \frac{-1}{m s} \\ 0 & 0\end{array}\right]$

\section{Sky-Hook Control Method}

The sky-hook control method is considered in the current work as a control algorithm due to its effectiveness and simplicity, were significant reduction in the resonant peaks of the sprung mass are reported in (Emanuele et al. 2008). This results a good ride quality (or comfort) by adjusting the sky-hook damping coefficient as the car body velocity and other conditions are changing. If the unsprung and sprung masses are separated, then the semi-active damper is in tension. Thus, the force utilized to the sprung mass is;

$$
f s k y=\operatorname{csky}(x \vec{b}-x w)
$$

where, Fsky is the sky-hook force next is to locate if the semi-active damper is able to supply a similar force. $f$ sky is the force utilized to the sprung mass. Since one can produce a power in the suitable direction, the only condition to correspond to the sky-hook suspension is,

$\mathrm{C}=\frac{\varepsilon_{s k} y^{x} x_{b}}{\left(x_{h}^{*}-x_{u}^{*}\right)}$

In this control algorithm two-state control scheme, named an On/Off control system, are considered. This control technique switches among high and low damping states so as to realize accepted body comfort. It is worth to confirm that when the outcome of the 2 speeds is positive, the semi-active damping power is proportional to the speed of the sprung mass. Furthermore, the semi-active damping power is at minimum. Where, Cmax and Cmin are the maximum and minimum damping constants of damper, respectively (and usually $C \max =C$ ). For semi-active simulation, selecting the maximum and minimum constants of damping amount conjointly plays a vital role for semi-active suspension control strategies design. Semi-active damping constants are selected utilizing two relationships as delineated by, $C_{\max }$ $=2000 \mathrm{~N} . \mathrm{s} / \mathrm{m}$ and $C_{\min }=1100 \mathrm{~N} . \mathrm{s} / \mathrm{m}$ (Gupta2015).

$c= \begin{cases}C \max , & \text { If } \dot{x} b *(x b-x w) \geq 0 \\ C \min , & \text { else } x \dot{b} *(x b-x w)<0\end{cases}$

\section{MEASURING DEVICES}

\section{Load Cell}

A load cell type (SS300-2ton) is a force-measuring transducer based on the use of strain gauges, which are manufactured from metal foil or semiconductor materials as shown in Figure (3). When the load cell is stretched or compressed by applied force, the strain gauges experience a strain, which is proportional to force in a load cell structure, and give an electrical resistance change. Fundamentally, the strain gauges experience a fractional change in resistance under the strain, which is not easily directly measured, therefore the strain gauges, used in load cell, are normally configured in a Wheatstone bridge circuit. The circuit can be used to convert the resistance change to a voltage change that is easier to measure. 


\section{Accelerometers (G-sensor)}

There are two reasons for using accelerometers. Firstly, an acceleration signal is used as an indicator for ride comfort. Secondly, car body and wheel unit velocity need to be measured and used in feedback control. Theoretically, a velocity signal could be obtained from an acceleration signal by an analogue or digital integrator. An accelerometer shown in figure(4) was used to measure the velocity of the system shown in figure(5).

\section{Knock sensor}

The piezoelectric type knock sensor shown in figure (6) is used in the present work. The sensor consists of a piezoelectric sensing crystal and a resister. When shakes the crystal creates a small amount of voltage. The knock sensor usually used in automotive and located on the engine block, cylinder head or intake manifold. Its function is to sense the vibrations caused by the engine knock or detonation.

\section{The Road Bump Excitation}

A road can be considered with the profile of harmonic sine waves, and therefore the wheel of the car is possibly considered a follower with freedom to proceed within the vertical direction solely. The road profiles utilized in this simulation were composed of step input excitations drawn from the criterion open normal distribution from specific intervals. The speed bump is $20 \mathrm{~km} / \mathrm{h}$ that passes over a bump of height $30 \mathrm{~mm}$ has been selected for simulation as can be shown in figure(7). A signal generator emits a step input. Equation of bump road is

$$
z_{0}=B-B \times(t t-3)^{2}
$$

\section{MATLAB Simulation}

To achieve the current work objectives of improving the passenger ride comfort under different road conditions, or simplified as passing over bump type road excitation, simulation by MATLAB was performed for both passive and semi-active quarter car systems using Skyhook On/Off controllers. The run time was set up to $10 \mathrm{~s}$ as the vehicle travelling at $20 \mathrm{~km} / \mathrm{h}$. The simulations were performed for the following components values: $m_{\mathrm{s}}=250 \mathrm{~kg}, m_{\mathrm{us}}=41$ $\mathrm{kg}, k_{\mathrm{s}}=37745.6 \mathrm{~N} / \mathrm{m}, k_{\mathrm{t}}=190000 \mathrm{~N} / \mathrm{m}, \mathrm{c}_{1}=2000 \mathrm{~N} . \mathrm{s} / \mathrm{m}$, and $\mathrm{c}_{2}=1100 \mathrm{~N} . \mathrm{s} / \mathrm{m}$.

\section{RESULTS AND DISCUSION \\ Quarter car Simulation results under road bump excitation}

Figure(8) shows a comparison between a semi-active system under the influence of Sky-hook control and a semi-active system without control. The results obtained theoretically revealed that there is a significant difference in the values of displacement as the control method used gives a maximum overshoot of $0.023 / \mathrm{m}$ at a time of 4.8 seconds and a maximum undershoot of $-0.006 \mathrm{~m}$ at the time of 5.3 seconds, and the time stability for semi-active suspension system was 6.6 seconds. For uncontrolled semi-active suspension system, the maximum overshoot is $0.026 \mathrm{~m}$ at a time of 4.7 seconds and the maximum undershoot is $-0.008 \mathrm{~m}$ at the time of 5.8 seconds, also the stability time of the system is 7 seconds. Through the results above, one can conclude that the way of the Sky-hook control gives better performance and thus provides comfort for the passenger in terms of short-time stability and maximum overshoot displacement.

Figure (9) shows the control method used in control of the unsprung mass displacement, where the maximum overshoot is $0.017 \mathrm{~m}$ at the time of 4.51 seconds, and the maximum undershoot is $-0.0038 \mathrm{~m}$ at the time of 5.1 seconds, and that the stability of an unsprung mass of 6.6 seconds is the same time stability of sprung mass displacement. 
The performance of semi-active suspension system was compared to the passive one. The maximum over shoot of displacement reduced to $53 \%$ because of continuous Sky-hook On/Off. The road bump caused high suspension deflection in a relatively short time. The sprung mass displacement is plotted in Figure(10) with time history during sustaining speed bump road with a speed of $20 \mathrm{~km} / \mathrm{h}$ for the car. And it was found that the Sky-hook algorithmic observer showed good estimation for the suspension system states for the controller as the excitation is traveling across the car speed road.

\section{CONCLUSIONS}

1. The conventional sky-hook offers best performance at low frequencies close to the first mode of resonance and reasonably good performance at higher frequencies as well.

2. The simulation results for both passive and semi-active (using sky-hook controller) suspension system exhibited apparent trade off in between displacement and acceleration. The improvements are reducing peak amplitude and settling time to 53\% and $67 \%$ respectively as compared with passive one.

3. Generally, there are no improvement for the velocity, but shows marginal improvement at higher frequency but lesser as compared to control strategy with acceleration.

4. The experimental results showed a great deal of correspond with the theoretical results obtained from the simulation process.

5. Control strategy with displacement offers improvement over semi-active damper and even exceeds the performance of MR damper at higher frequencies, this method showed good experimental results in reducing the vibration capacity, also to the stability time.

6. In general, the test rig was in good compatibility with the theoretical results. And since the test rig is designed with flexibility to different suspension system under different design conditions, therefore this test rig can be used as a universal one for different design conditions and/or control strategy.
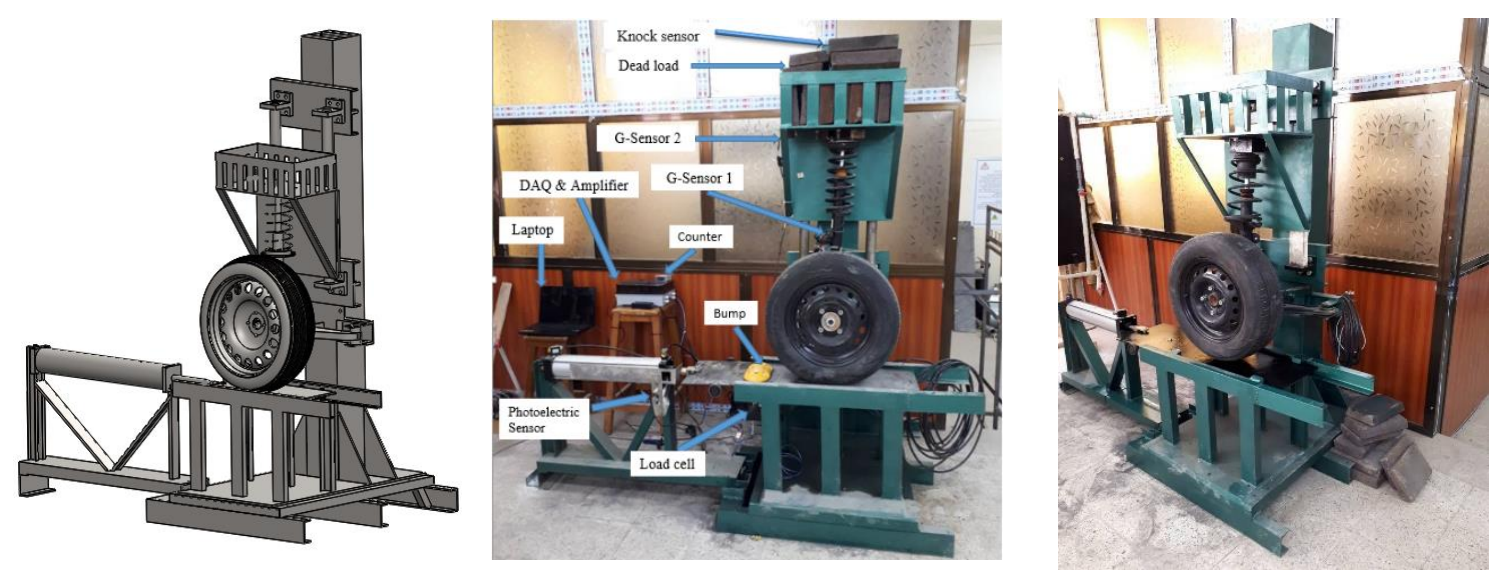

Fig. (1) Quarter Car Test Rig 

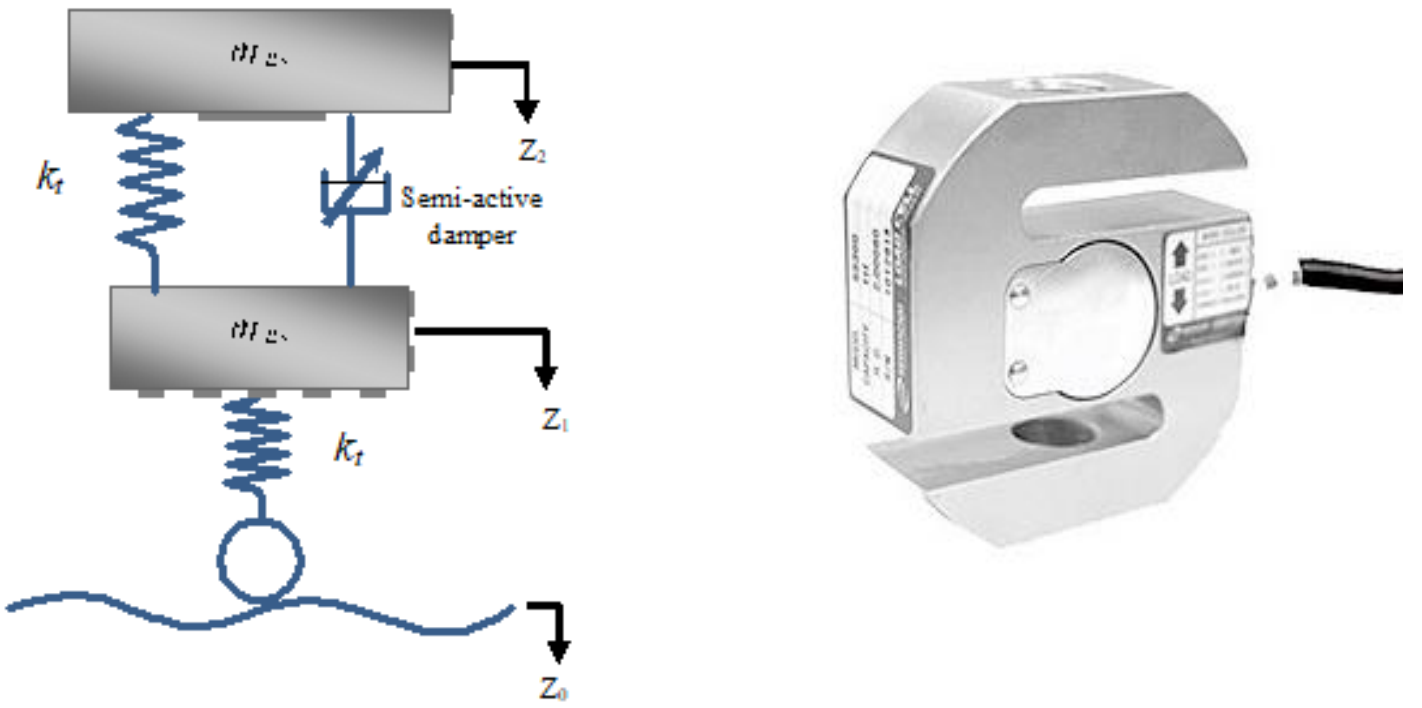

Fig. (2) Model of quarter car with a semi- Fig. 3: Load cell type SS300-2 ton. active suspension

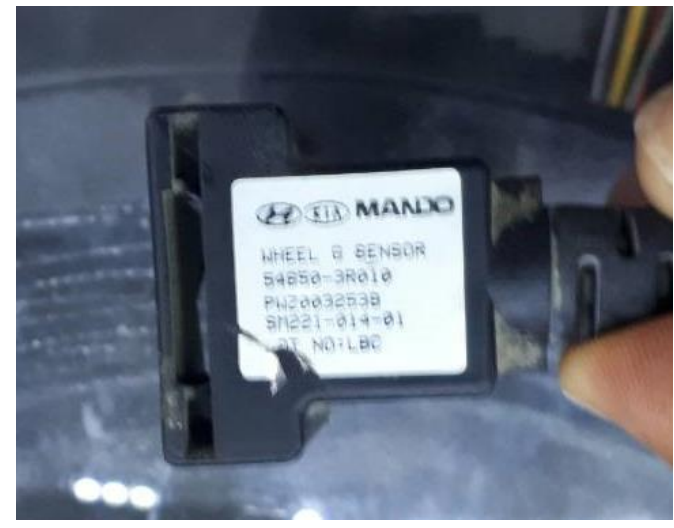

Fig.(4): Accelerometer G-sensor

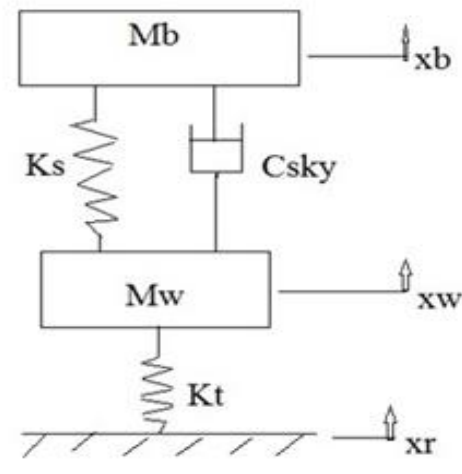

Fig. (5): Practical use of the control system

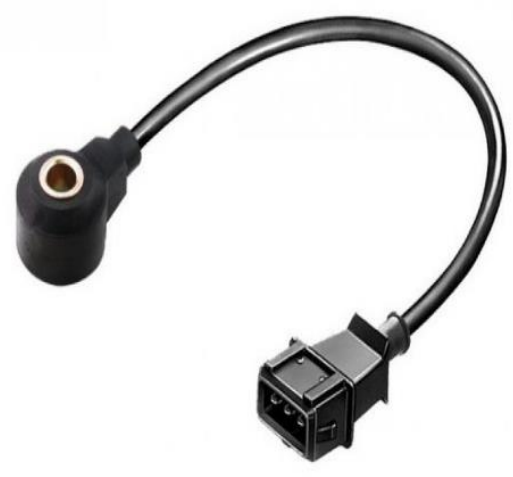

Fig. (6): Knock sensor 

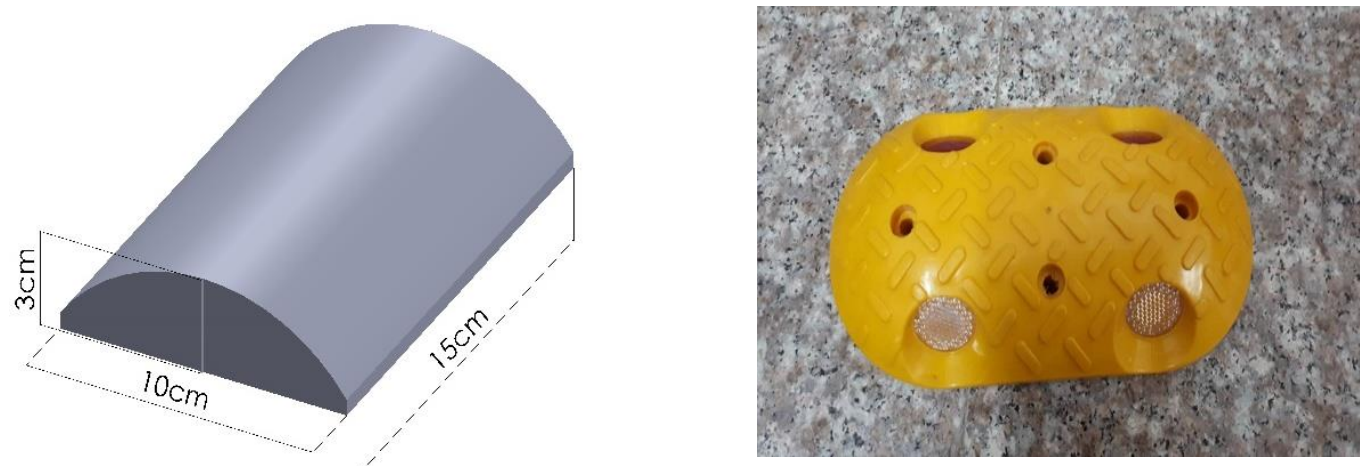

Fig.(7): Bumps road profile.

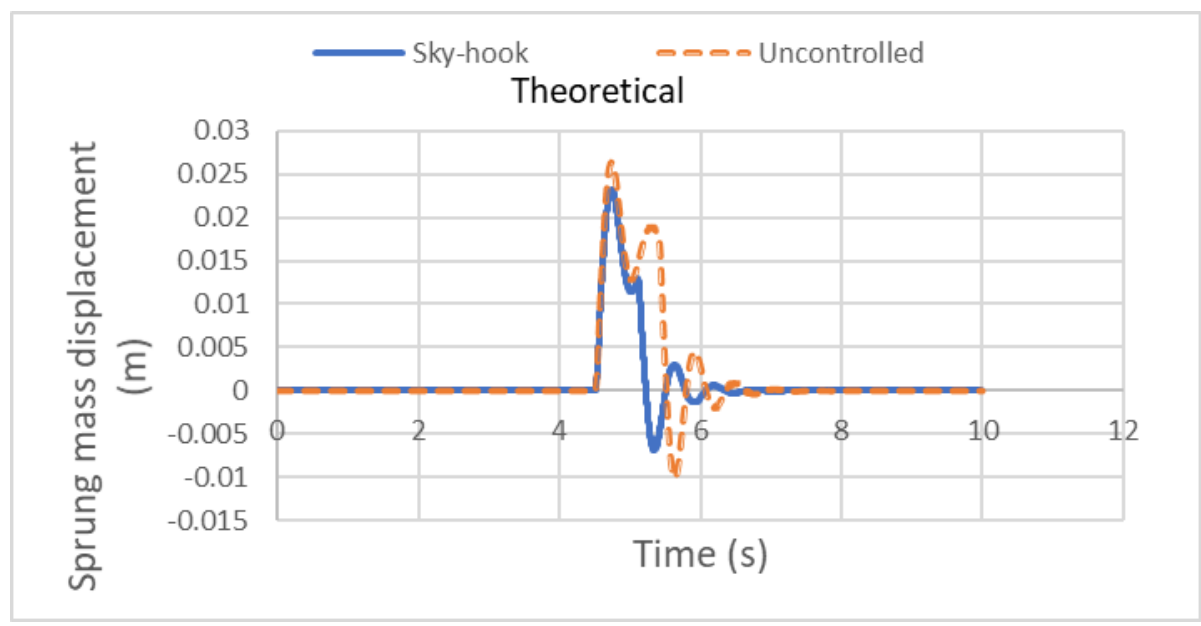

Fig.(8): Comparison between controlled and uncontrolled theoretical results.

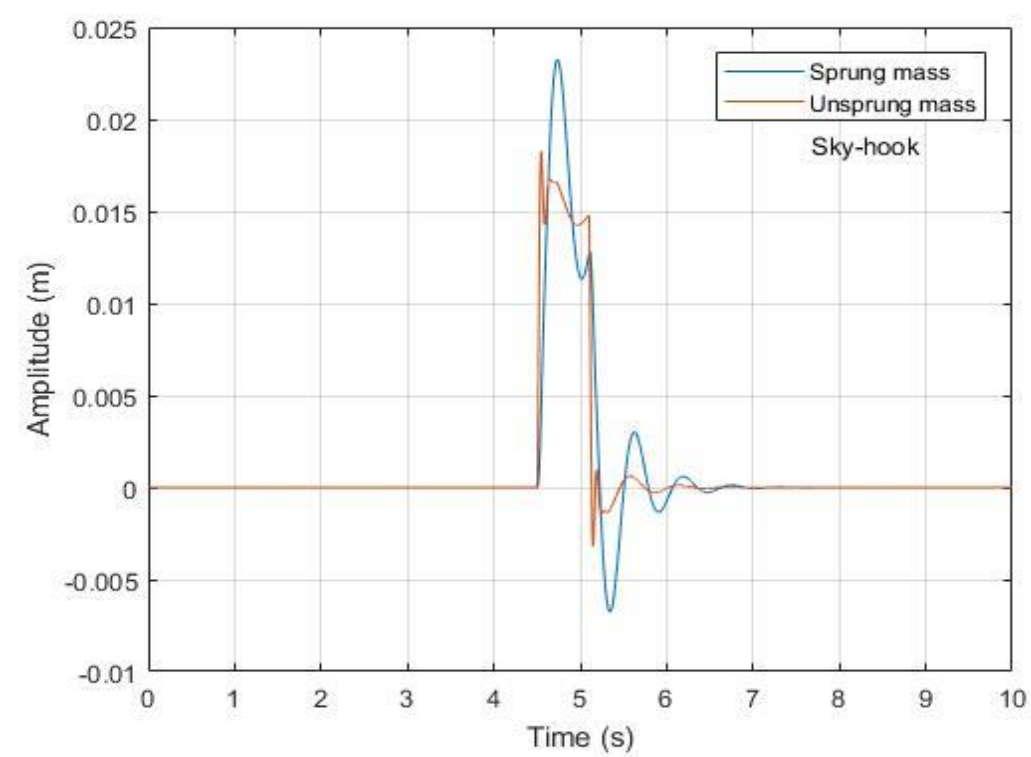

Fig.(9): Displacements for Sprung mass and unsprung mass using skyhook control 


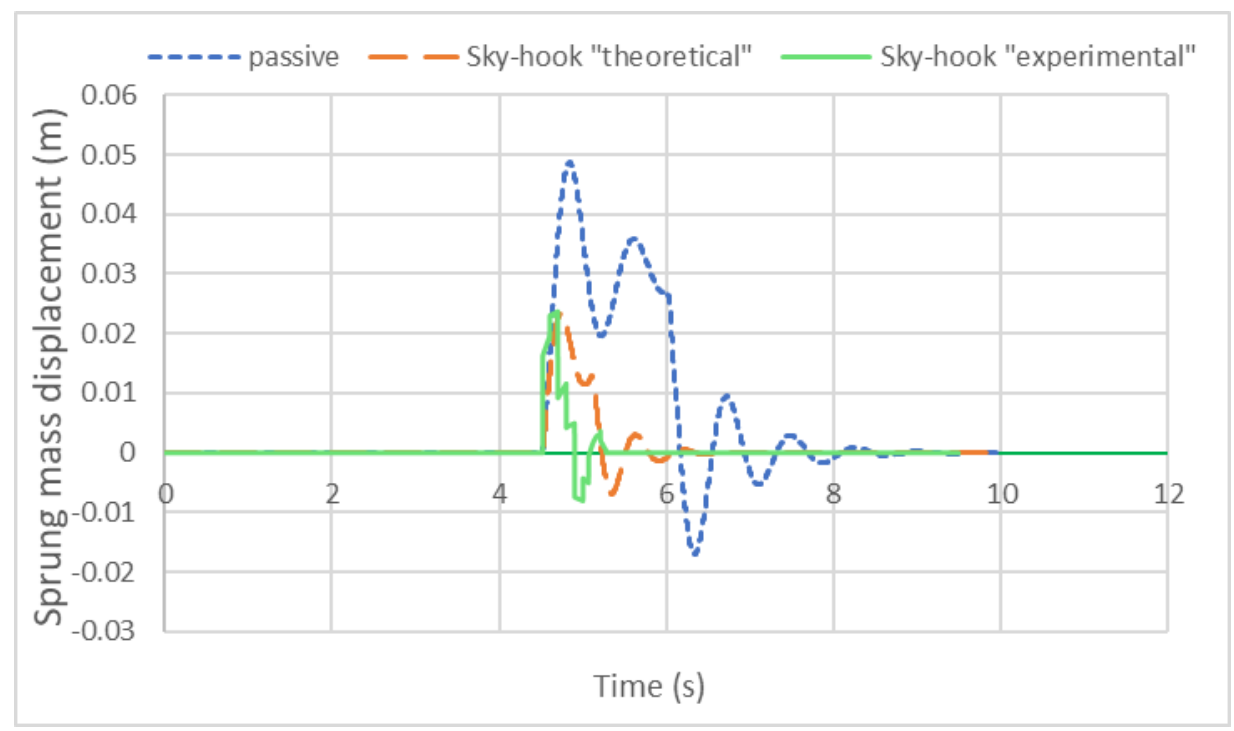

Fig.(10): Theoretical and experimental results for passive and semi-active suspension system.

\section{REFERENCES}

S. Kashem, R. Nagarajah, and M. Ektesabi., Vehicle Suspension Systems and Electromagnetic Dampers. Springer Singapore,2018.

A. A. Aly, "Car Suspension Control Systems : Basic Principles," Int. J. Control. Autom. Syst., vol. 1, no. 1, 2012.

SM. Savaresi, C. Vassal, C. Spelta, O, Sename, and L, Dugard., Semi-active suspension control design for vehicles. Elsevier, 2010.

N. Bangsing, Sularso, K. Bagiasna, and Y. Y. Nazaruddin, "An Experimental Investigation Into The Design Of A Robust Semi-Active Suspension System For A Quarter-Car Model,” no. June, pp. 971-975, 2011.

G. Priyandoko, M. Mailah, and H. Jamaluddin, "Vehicle Active Suspension System Using Skyhook Adaptive Neuro Active Force Control," Mech. Syst. Signal Process., vol. 23, no. 3, pp. 855-868, 2009.

J. Swevers, C. Lauwerys, B. Vandersmissen, M. Maes, K. Reybrouck, and P. Sas, "A Model-Free Control Structure For The On-Line Tuning Of The Semi-Active Suspension Of A Passenger Car," Mech. Syst. Signal Process., vol. 21, no. 3, pp. 1422-1436, 2007. 
Suh, M. S., and M. S. Yeo, "Development Of Semi-Active Suspension Systems Using ER Fluids For The Wheeled Vehicle." Electro-Rheological Fluids And MagnetoRheological Suspensions. 2000. 775-782.

M. A. Eltantawie, "Decentralized Neuro-Fuzzy Control For Half Car With SemiActive Suspension System,” vol. 13, no. 3, pp. 423-424, 2012.

A. Malekshahi and M. Mirzaei, "Designing A Non-Linear Tracking Controller For Vehicle Active Suspension Systems Using An Optimization Process," vol. 13, no. 2, pp. 263-264, 2012.

A. L. Do, C. Spelta, S. Savaresi, O. Sename, L. Dugard, and D. Delvecchio, “An LPV Control Approach For Comfort And Suspension Travel Improvements Of SemiActive Suspension Systems," Proc. IEEE Conf. Decis. Control, pp. 5560-5565, 2010 .

Guglielmino, Emanuele, Tudor Sireteanu, Charles W. Stammers, Gheorghe Ghita, and Marius Giuclea. Semi-Active Suspension Control: Improved Vehicle Ride And Road Friendliness. Springer Science \& Business Media, 2008.

N. Gupta, "Development of Semi-Active Control System for Hydraulic Dampers," 2015. 